\title{
Optical biosensor based on enhanced surface plasmon resonance: theoretical optimization
}

\author{
Kada A. Meradi ${ }^{1}$. Fatima Tayeboun ${ }^{2}$ - Amine Guerinik ${ }^{3}$ - Zaky A. Zaky ${ }^{4}$ Arafa H. Aly ${ }^{4}$
}

Received: 5 November 2021 / Accepted: 24 December 2021 / Published online: 20 January 2022

(c) The Author(s) 2022

\begin{abstract}
In this article, a theoretical design of enhanced surface plasmon resonance is proposed. The suggested sensor is composed of titanium, silver, graphene, photonic crystal, and a sensing layer. This structure is used to detect cancer cells and hemoglobin in blood plasma based on their refractive indices. Different parameters such as sensitivity and figure of merit are studied at an operating wavelength of $633 \mathrm{~nm}$. The recorded sensitivity and figure of merit are 72 degrees/RIU and $346 \mathrm{RIU}^{-1}$. The ability of the proposed sensor to detect cancer cells and blood plasma concentration will be investigated.
\end{abstract}

Keywords Plasmon resonance $\cdot$ Photonic crystals $\cdot$ Cancer cells $\cdot$ Sensitivity

\section{Introduction}

Surface Plasmon Resonance (SPR) is a collective oscillation of propagated free electrons at the interface between a metallic thin sheet and a dielectric layer (Choi et al. 2011; Balakrishnan et al. 2016; Singh et al. 2015; Singh and Black 2018). SPR is a physical effect that allows researchers to investigate real-time biomolecular interactions. This approach responds well to changes in the refractive index of the sensing material. This response happens as a result of changing the optical properties of the attached biomolecules to the surface (Foley et al. 2015; Kim 2010; Akimov 2018; Wu et al. 2016). SPR biosensors have been used in various applications such as plasmonic detectors, optical polarization encoding, sensing technology, and bio-photonic sensors (Dai et al. 2015; Xiang et al. 2014; Ooi et al. 2012; Singh et al. 2012; Esteban et al. 2011). Thin films of metals such as aluminum, gold, or silver can be utilized to determine molecular concentration for biosensing in conventional SPR (Homola 2008; Xinglong et al. 2003). The SPR angle is the angle

Arafa H. Aly

arafaaly@ aucegypt.edu; arafa.hussien@ science.bsu.edu.eg

1 Institute of Science and Technology, University of Ain Temouchent, BP 284,

46000 Aïn Témouchent, Algeria

2 University Djillali Liabes, 22000 Sidi-Bel-Abbes, Algeria

3 Physics Department, Djillali Liabes University of Sidi Bel, 22000 Abbes, Algeria

4 TH-PPM Group, Physics Department, Faculty of Sciences, Beni-Suef University, Beni Suef, Egypt 
of incidence in which minimum reflected light intensity happens between the metal and dielectric boundary.

There are different ways to enhance the performance of biosensors. Abdulhalim et al. improved the performance of the biosensor by combining a layer of high refractive index with the metallic sheet (Shalabney and Abdulhalim 2011; Lahav et al. 2008). Guerinik et al. introduced an $\mathrm{Al}_{\mathrm{x}} \mathrm{Ga}_{1-\mathrm{x}} \mathrm{As} 70 \% \mathrm{Al}$ on top of the gold/silver sheet as an SPR biosensor (Guerinik and Tayeboun 2020). Also, Chabot et al. manufactured a responsive sensor by utilizing SPR (Chabot et al. 2012). Recently, Graphene appeared as an excellent alternative to enhance biosensors' sensitivity because of its substantial adsorption property (Wu et al. 2010; Zaky and Aly 2021a, b; Liu et al. 2019; Zaky et al. 2021a). Graphene-on-silver design improved by a titanium layer (Ti) is employed for superior to prism glass adherence (Choi et al. 2011).

One-dimensional photonic crystals (1D-PhC) are periodic constructions in which the refractive index alters periodically through the structure (Zaky and Aly 2021c, 2020; Aly et al. 2021a, 2020; Zaky et al. 2020, 2021b). The refractive index of the sensing substance of the $\mathrm{PhC}$ or the defect layer can change the resonance wavelength (Prather et al. 2009; Aly et al. 2008, 2021b; Abd El-Ghany et al. 2020; Zaky et al. 2021c, d, e; Tammam et al. 2021). Hybrid configurations composed of two different structures of metal and photonic crystal (PhC) have also drawn much consideration in the latest times (Meradi et al. 2016; Sabra et al. 2018). Moradi et al. have described a susceptible sensor using a 1D-PhC with a sensitivity of 240 degrees/RIU (Meradi et al. 2016).

The present work reports a biosensor deposited on BK7 glass with a graphene-on-silvertitanium structure combined with a $1 \mathrm{D}-\mathrm{PhC}$ to enhance the overall performance of the biosensor. This study assumes a $633 \mathrm{~nm}$ as a fixed wavelength, which is the typical emission wavelength of a He-Ne laser (Wu et al. 2016; Zeng et al. 2015; Sahu et al. 2009). The optimized structure is exploited for detecting the blood plasma and different cancer cells. Various cancer cells or blood plasmas located in analyte consequence in a displacement of the reflection ranges of our arrangements. The variation in the blood plasma's concentration or the cancer cells triggers a significant change to the resonant dips. Thus, by examining the suggested biosensor structures' reflectance spectra, it is feasible to calculate the various blood plasma concentrations and detect different cancer cells.

The novelty of this study is that a significant improvement is observed in the proposed biosensor's FoM compared with the conventionally reported biosensors, as clear in Table 3.

\section{Description and analysis of the structure}

The suggested SPR-PhC sensor is composed of titanium (Ti), silver (Ag), graphene, photonic crystals (PhCs), and sensing layer as clear in Fig. 1A. These materials are deposited on a BK7 glass prism with a refractive index RI of $\mathrm{n}_{1}=1.515$ (Wu et al. 2017; Sreekanth et al. 2013). Ti layer has a refractive index of $2.7043+\mathrm{i} 3.7657$ and a thickness of $1 \mathrm{~nm}$ (Johnson and Christy 1974). This layer of $\mathrm{Ti}$ is utilized to enhance the Ag layer's adherence to the optical prism glass (Choi et al. 2011). SPR sensor coated with Ag has better responsive than metals, however, silver is susceptible to oxidation. To avoid the oxidation of silver, Ag will be coated with a graphene layer. The refractive index of the Ag layer at the used wavelength is $0.059+\mathrm{i} 4.243$ (Choi et al. 2011; Choi and Byun 2010), and its optimum thickness is $49.5 \mathrm{~nm}$. The graphene's refractive index and thickness are respectively $\mathrm{n}_{\mathrm{G}}=3.0+\mathrm{i} 1.1491$ and $\mathrm{d}_{\mathrm{G}}=0.34 \mathrm{~nm}$ (Choi et al. 2011; Wu et al. 2017). A 1D-PhC structure contains $\mathrm{N}$ pairs of titanium dioxide-silica 

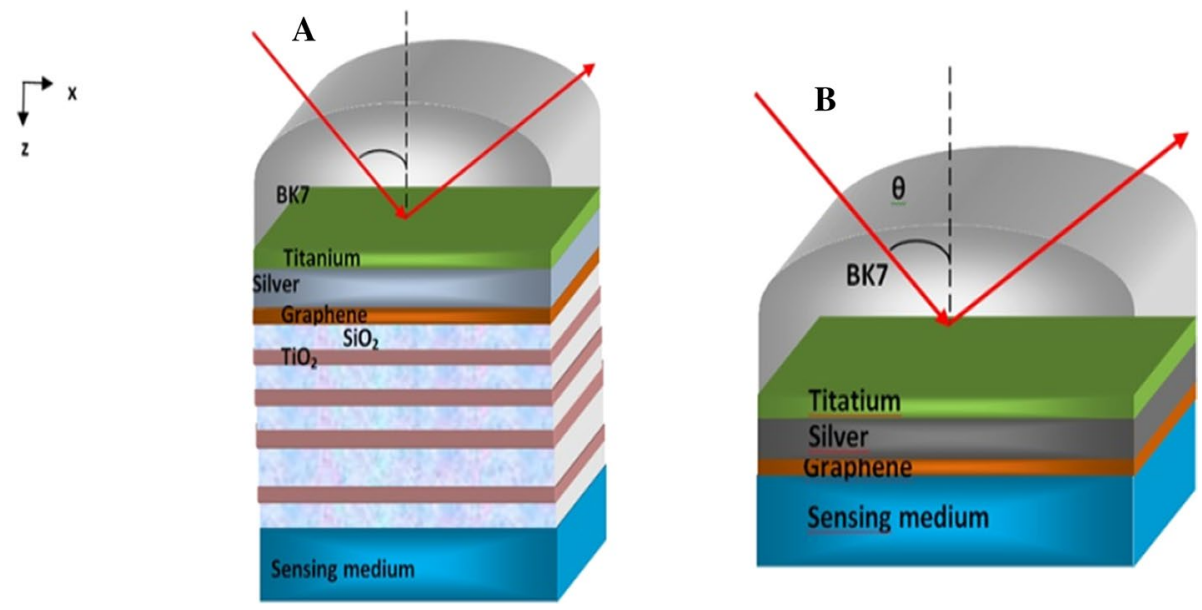

Fig. 1 A Schematic diagram of suggested SPR-PhC multilayered configuration with $\mathrm{N}$ pairs of $\mathrm{SiO}_{2}-\mathrm{TiO}_{2}$ layers, and $\mathbf{B}$ the configuration of SPR graphene-based sensor with titanium-silver

layers $(\mathrm{SiO} 2-\mathrm{TiO} 2)^{\mathrm{N}}$ with $\mathrm{n}_{\mathrm{SiO} 2}=1.451, \mathrm{n}_{\mathrm{TiO} 2}=2.232$ (Gao et al. 2012; Siefke et al. 2016), $\mathrm{d}_{\mathrm{SiO} 2}=\lambda / 4 \mathrm{n}_{\mathrm{SiO} 2}$ and $\mathrm{d}_{\mathrm{TiO} 2}=\lambda / 4 \mathrm{n}_{\mathrm{TiO} 2}$. Finally, we used water with a refractive index of 1.333 as a reference value for calibration. To compare our results, a conventional SPR structure will be studied as clear in Fig. 1B.

A monochromatic electromagnetic wave with wavelength $\lambda=633 \mathrm{~nm}$ propagates through the optical prism and is entirely reflected at the metal boundary creating an evanescent wave. The evanescent wave can penetrate the graphene and propagate along the $x$-axis with the wave vector constant of the following equation (Foley et al. 2015; Wu et al. 2016):

$$
\mathrm{k}_{\mathrm{x}}=\frac{2 \pi n_{1}}{\lambda} \sin \theta
$$

where $\theta$ is the incidence angle of the electromagnetic wave. The surface plasmon propagation constant $k_{\mathrm{sp}}$ is termed as (Foley et al. 2015):

$$
\mathrm{k}_{\mathrm{sp}}=\frac{2 \pi}{\lambda} \sqrt{\frac{\mathrm{n}_{\mathrm{m}}^{2} \mathrm{n}_{\mathrm{t}}^{2}}{\mathrm{n}_{\mathrm{m}}^{2}+\mathrm{n}_{\mathrm{t}}^{2}}},
$$

where $n_{m}$ is the refractive index for the metal and $n_{t}$ is the refractive index of the detecting sample material $\left(\mathrm{n}_{\mathrm{t}}\right)$. SPR can be excited when the wave vector of the plasmon surface matches the wave vector of the incident electromagnetic wave. As a result, the incident electromagnetic wave resonantly couples with the plasmon surface, and a large enhancement of the electric field is realized with a minimum reflectance.

Studying the power of the reflected electromagnetic wave from an N-layer structure displayed in Fig. 1A for a TM electromagnetic wave polarization, the reflectance (R), is obtained by Guerinik and Tayeboun (2020).

$$
R=\left|\frac{\left(M_{11}+M_{12} q_{N}\right) q_{1}-\left(M_{21}+M_{22} q_{N}\right)}{\left(M_{11}+M_{12} q_{N}\right) q_{1}+\left(M_{21}+M_{22} q_{N}\right)}\right|^{2},
$$




$$
\begin{gathered}
M_{i j}=\left(\prod_{k=2}^{N-1} M_{k}\right)_{i j} i, j=1,2, \\
M_{k}=\left(\begin{array}{cc}
\cos \beta_{k} & \frac{-i \sin \beta_{k}}{q_{k}} \\
-i q_{k} \sin \beta_{k} & \cos \beta_{k}
\end{array}\right), \\
q_{k}=\frac{\sqrt{\varepsilon_{k}-n_{1}^{2} \sin ^{2} \theta}}{\varepsilon_{k}}, \\
\beta_{k}=d_{k}\left(\frac{2 \pi}{\lambda}\right) \sqrt{\varepsilon_{k}-n_{1}^{2} \sin ^{2} \theta} .
\end{gathered}
$$

The $\mathrm{k}_{\mathrm{th}}$ layer has an electric permittivity $\left(\varepsilon_{\mathrm{k}}\right)$ and thickness $\left(\mathrm{d}_{\mathrm{k}}\right)$, where $\mathrm{k}$ is from 2 up to $\mathrm{N}-1$. Numerous factors are utilized to evaluate the performance of an SPR sensor. The fraction of shift of the resonance angle $\left(\Delta \theta_{\mathrm{sp}}\right)$ to the change in the analyte refractive index $\left(\Delta \mathrm{n}_{\mathrm{t}}\right)$ is defined as sensitivity (S) (Verma et al. 2011):

$$
\mathrm{S}=\frac{\Delta \theta_{\mathrm{sp}}}{\Delta \mathrm{n}_{\mathrm{t}}}(\text { degree } / \mathrm{RIU}) .
$$

However, another critical parameter for evaluating is the figure of merit (FOM) (Meshginqalam and Barvestani 2018):

$$
\mathrm{FOM}=\frac{\mathrm{S}}{\mathrm{FWHM}}\left(\mathrm{RIU}^{-1}\right),
$$

where FWHM is the full-width at half maximum of the resonant dip. To improve the SPR sensor's resolution, it is required to reduce the FWHM of the reflectance dips to reduce the ambiguity in the resonance dip's fixation.

\section{Results and discussions}

The SPR excitation is a result of the total internal reflection (TIR). The TIR of reflectance spectra of SPR-PhC structure at $\mathrm{N}=6$ takes place at the critical angles $\theta_{\mathrm{c}} \sim 69.95^{\circ}$ for $\mathrm{n}_{\mathrm{t}}=1.423$ and $\theta_{\mathrm{c}} \sim 61.65^{\circ}$ for $\mathrm{n}_{\mathrm{t}}=1.333$, as clear in Fig. $2 \mathrm{~A}$. The $\theta_{\mathrm{c}}$ value is associated with the refractive index of the prism corresponding values $\left(\mathrm{n}_{1}\right)$ and the refractive index of the analyte $\left(n_{t}\right)$. The SPR occurs at angles $\theta_{s p}=71.55^{\circ}$ and $\theta_{s p}=74.24^{\circ}$ for $n_{t}=1.333$ and $\mathrm{n}_{\mathrm{t}}=1.423$, respectively, as clear in Fig. 2A.

Figure $2 \mathrm{~B}$ shows the reflectance spectra of the conventional SPR. TIR takes place at the critical angle $\left(\theta_{\mathrm{c}} \sim 69.99^{\circ}\right.$ for $\mathrm{n}_{\mathrm{t}}=1.423$ and $\theta_{\mathrm{c}} \sim 61.64^{\circ}$ for $\left.\mathrm{n}_{\mathrm{t}}=1.333\right)$. The minimum reflected intensity confirms the excitation of the SPR. For the conventional SPR the resonance is obtained at angles $\theta_{\mathrm{sp}}=68.23^{\circ}$ and $\theta_{\mathrm{sp}}=85.21^{\circ}$ for the water-sensing layers with $\mathrm{n}_{\mathrm{t}}=1.333$ and $\mathrm{n}_{\mathrm{t}}=1.423$, respectively.

The SPR-PhC structure recorded sensitivity of 29.9 degrees/RIU and FoM of 83.7 $\mathrm{RIU}^{-1}$. On the other hand, the conventional SPR structure recorded a sensitivity of 188.5 degrees/RIU and FoM of 119.6 RIU ${ }^{-1}$. From the first study, the SPR-PhC structure 

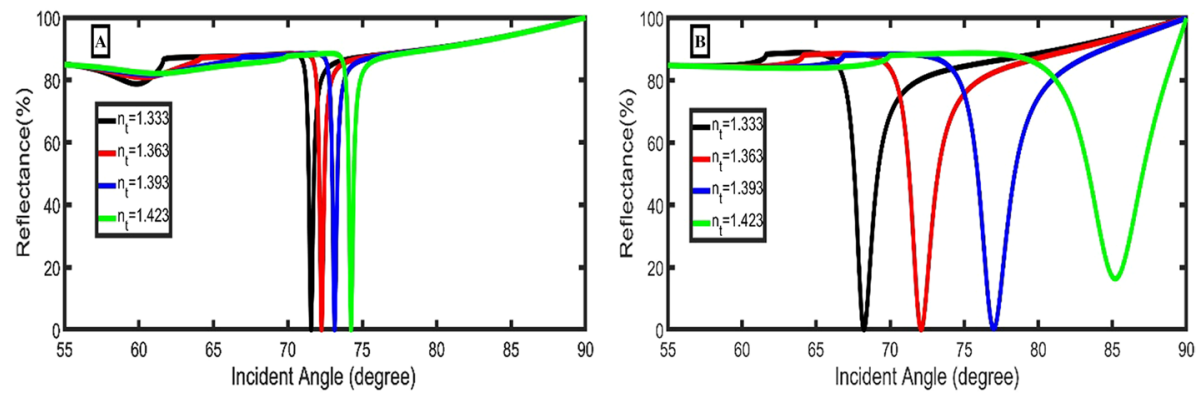

Fig. 2 The reflectance of the A SPR-PhC structure at $\mathrm{N}=6, \mathbf{B}$ conventional SPR structure as a function of the incidence angle for different analyte refractive indices

beats the conventional SPR structure in terms of the FWHM, but the conventional SPR structure beats in terms of sensitivity and FoM. In the following study, the geometrical parameters of the SPR-PhC structure will be optimized to achieve the highest performance with the lowest FWHM.

Because optimizing the geometrical parameters of the SPR-PhC structure will improve the sensitivity of SPR, the number of periods and the thickness of the PhC layers will be studied at different values. According to the reflectance spectra in Fig. 3A, by increasing the number of periods from 4 to 9, the width of the dips decreases. As clear in Fig. 3B, the structure records the highest sensitivity and high FoM at $\mathrm{N}=4$ and will be the optimum condition.

Figure 4 illustrates the performance of SPR-PhC for different thicknesses of PhC layers (SiO2-TiO2) by changing $n_{t}$ from 1.333 to 1.423 . The sensitivity and FoM of the model are calculated when a beam of light with a wavelength of $633 \mathrm{~nm}$ is incident into it. In Fig. 4, the maximum sensitivity and FoM were recorded to be as high as $73.7 \mathrm{deg} / \mathrm{RIU}$ and 196 $\mathrm{RIU}^{-1}$ at an optimal thickness of $0.4 * \mathrm{~d}$. For lower values than $0.4 * \mathrm{~d}$, the resonant dips disappear. The optimized structure consists of a prism BK7, Ti, Ag, graphene, and four pairs of $\mathrm{SiO}_{2}-\mathrm{TiO}_{2}$ layers. The remaining parameters are the same as those in Fig. 1A, while the thicknesses of each layer in the $\mathrm{PhC} \mathrm{SiO}_{2}-\mathrm{TiO}_{2}$ are respectively, $\mathrm{d}_{\mathrm{SiO} 2}=0.4 * \lambda / 4 * \mathrm{n}_{\mathrm{SiO} 2}$, $\mathrm{d}_{\mathrm{TiO} 2}=0.4 * \lambda / 4 \mathrm{n}_{\mathrm{TiO} 2}$.
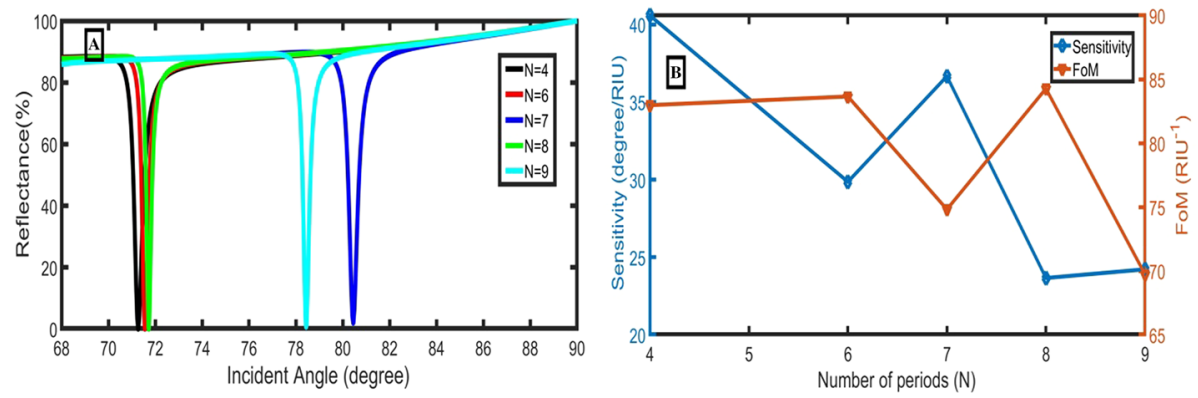

Fig. 3 A The reflectance of the SPR-PhC structure at $n_{t}=1.333$ as a function of the incidence angle for a different number of periods, and $\mathbf{B}$ sensitivity and FoM of the sensor at different $\mathrm{N}$ by changing $\mathrm{n}_{\mathrm{t}}$ from 1.333 to 1.423 
Fig. 4 The sensitivity and FoM of the sensor at $\mathrm{N}=4$ for different thicknesses of PhC layers by changing $\mathrm{n}_{\mathrm{t}}$ from 1.333 to 1.423

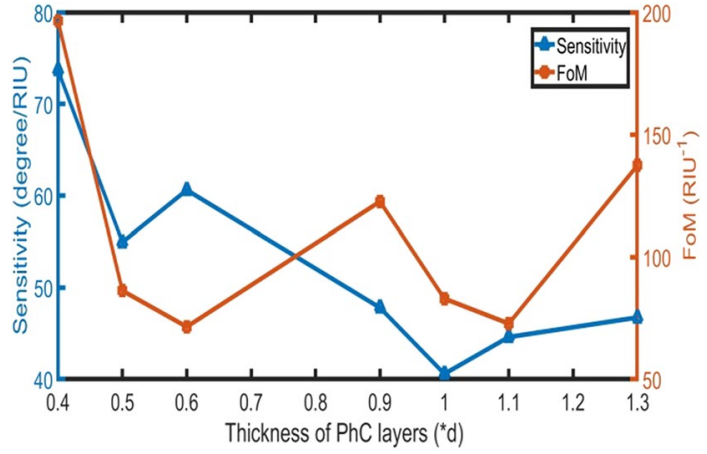

Because some biofluids such as hemoglobin, blood glucose, and cancer cells have their refractive indices spread over $n_{t}$ values between 1.3 and 1.42 (El-Khozondar et al. 2019; Aly and Zaky 2019; Ramanujam et al. 2019; Bijalwan and Rastogi 2018), we will focus the numerical simulations on this range. This allows us to say that our proposed sensor can be used for bio-detection. To justify this choice, we have analyzed our sensor's performance for the blood plasma cell and cancer detection application. The refractive indices of the various blood plasma cells are taken from reference (El-Khozondar et al. 2019). As clear in Table 1, the refractive index of blood plasma can be calculated as a function of plasma concentration $\left(\mathrm{C}_{\mathrm{p}}\right)$ as the following (El-Khozondar et al. 2019):

$$
n_{t}=1.32459+0.001942 C_{p}
$$

We can see that the resonance angle moves towards higher angles as much as the plasma concentration increases because the refractive index of the blood changes as much as the concentration changes as clear in Fig. 5.

The sensitivity of this bio-sensor increases by increasing the plasma concentrations. Besides, the FoM of the proposed structure is very high. The calculated parameters describe the potential of the proposed sensor for different concentrations of the blood plasma cell, particularly the most concentrated. The calculated highest sensitivity of the sensor is $72 \mathrm{deg} / \mathrm{RIU}$ with a FoM of $345.8 \mathrm{RIU}^{-1}$ (Table 2).

We have also used this structure to detect cancer cells. Figure 6 illustrates the different reflectance spectra for different angles of incidence for various cancer and healthy cells (zero cancer), which are considered reference samples. We observe that $\theta_{\mathrm{sp}}$ changes when different cells are present. The highest sensitivity is $71.5 \mathrm{deg} / \mathrm{RIU}$ with a FoM of $271.5 \mathrm{RIU}^{-1}$. These results describe the potential of the proposed sensor to sense blood plasma and different

Table 1 The sensitivity and FoM of the proposed sensor for different concentrations of blood plasma

\begin{tabular}{llll}
\hline Blood plasma & Refractive index $\left(\mathrm{n}_{\mathrm{t}}\right)$ & $\begin{array}{l}\text { Sensitivity } \\
(\mathrm{deg} / \mathrm{RIU})\end{array}$ & FoM $\left(\mathrm{RIU}^{-1}\right)$ \\
\hline $0 \mathrm{~g} / \mathrm{L}$ & 1.32459 & - & - \\
$10 \mathrm{~g} / \mathrm{L}$ & 1.34401 & 58.3 & 161.4 \\
$20 \mathrm{~g} / \mathrm{L}$ & 1.36343 & 61.1 & 183.1 \\
$30 \mathrm{~g} / \mathrm{L}$ & 1.38285 & 64.1 & 213.0 \\
$40 \mathrm{~g} / \mathrm{L}$ & 1.40227 & 67.7 & 259.9 \\
$50 \mathrm{~g} / \mathrm{L}$ & 1.42169 & 72.0 & 345.8 \\
\hline
\end{tabular}


Fig. 5 The reflectance of the SPR-PhC structure as a function of the incidence angle for a different concentration of blood plasma values at a thickness of each layer in the $\mathrm{PhC}=0.4 * \mathrm{~d}$

Table 2 The sensitivity and figure of merit of the sensor for different cancer cells (Aly and Zaky 2019; Ramanujam et al. 2019):

Fig. 6 The reflectance of the SPR-PhC structure as a function of the incidence angle for different cancer cells at a thickness of each layer in the $\mathrm{PhC}=0.4 * \mathrm{~d}$

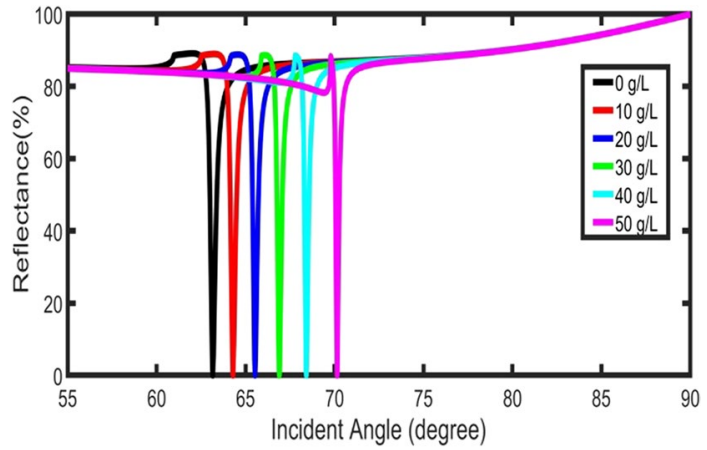

\begin{tabular}{llll}
\hline Cells & $\mathrm{n}_{\mathrm{t}}$ & $\begin{array}{l}\text { Sensitivity }(\mathrm{deg} / \\
\text { RIU) }\end{array}$ & FoM $\left(\mathrm{RIU}^{-1}\right)$ \\
\hline Normal cell & 1.350 & - & - \\
Jurkat cell & 1.390 & 69.3 & 241.1 \\
Hela cell & 1.392 & 69.7 & 246.1 \\
PC12 cell & 1.395 & 70.3 & 253.9 \\
MDA-MB-231 & 1.399 & 71.1 & 265.3 \\
MCF-7 cell & 1.401 & 71.5 & 271.5 \\
\hline
\end{tabular}

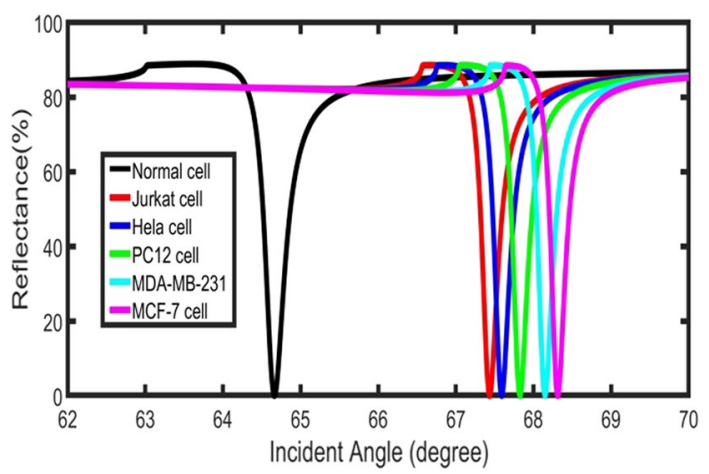

cancer cells. Finally, we can say that the performance of the proposed structure for detecting blood plasma is higher than the performance for cancer cell detection.

Based upon this investigation, we obtain a considerable sensitivity of $73.7 \mathrm{deg} / \mathrm{RIU}$ and FoM of $346 \mathrm{RIU}^{-1}$, as clear in Table 3. A significant improvement is observed in the proposed biosensor's FoM compared with the conventionally reported biosensors. 
Table 3 Comparison of different performance parameters of the suggested SPR-PhC with other reported SPR biosensors

\begin{tabular}{lll}
\hline References & $\begin{array}{l}\text { Sensitivity } \\
\text { (degree/RIU) }\end{array}$ & FoM $\left(\mathrm{RIU}^{-1}\right)$ \\
\hline Kushwaha et al. (2018) & 101.6 & 15.1 \\
Rahman et al. (2017a) & 80.7 & - \\
Maurya and Prajapati (2016) & 64.4 & 184.0 \\
Rahman et al. (2017b) & 87.8 & - \\
Ouyang et al. (2016) & $\sim 126.0$ & $\sim 6.4$ \\
Verma et al. (2015) & 68.0 & - \\
Rahman et al. (2020) & 94.3 & - \\
Our work & 72 & 346 \\
\hline
\end{tabular}

\section{Conclusion}

In these simulations, a novel design achieved a much sharper SPR compared to other structures. Besides, it can have a high sensitivity and FoM. The proposed configuration provides an innovative idea of using the enhanced SPR-PhC structure to excite plasmonic modes. Further, the applications of this structure as blood plasma and cancer cell sensors were studied. The highest sensitivity is $72.0 \mathrm{deg} / \mathrm{RIU}$ with a FoM of $345.8 \mathrm{RIU}^{-1}$ and $71.5 \mathrm{deg} /$ RIU with a FoM of $271.5 \mathrm{RIU}^{-1}$ for blood plasma and cancer cells sensor, respectively. The sensitivity of this bio-sensor increases by increasing the plasma concentrations. The optimizations of different parameters are done by using the TMM code. Besides, the FoM of the proposed structure is very high. These results cleared the proposed biosensor's potential for sensing the different blood plasma concentrations and various cancer cells.

Acknowledgments This work was produced with the financial support of the Academy of Scientific Research and Technology of Egypt; ScienceUP/GradeUp initiative: Grant. Agreement No (7859). Its contents are the sole responsibility of the authors and do not necessarily reflect the views of the Academy of Scientific Research and Technology. The author thanks the reviewers and editors for improving this article.

Author contributions All authors co-implemented the computer code, co-performed the numerical simulations, co-analyzed the data, co-wrote and revised the main manuscript text. All authors contributed equally.

Funding Open access funding provided by The Science, Technology \& Innovation Funding Authority (STDF) in cooperation with The Egyptian Knowledge Bank (EKB). The authors declare no Fund.

Availability of data, code, and material Requests should be addressed to any author.

\section{Declarations}

Conflicts of interest The authors declare no conflicts of interest.

Consent to participate Not Applicable.

Consent for publication Not Applicable.

Ethics declarations This article does not contain any studies involving animals or human participants performed by any of the authors.

Open Access This article is licensed under a Creative Commons Attribution 4.0 International License, which permits use, sharing, adaptation, distribution and reproduction in any medium or format, as long as you give appropriate credit to the original author(s) and the source, provide a link to the Creative Commons 
licence, and indicate if changes were made. The images or other third party material in this article are included in the article's Creative Commons licence, unless indicated otherwise in a credit line to the material. If material is not included in the article's Creative Commons licence and your intended use is not permitted by statutory regulation or exceeds the permitted use, you will need to obtain permission directly from the copyright holder. To view a copy of this licence, visit http://creativecommons.org/licenses/by/4.0/.

\section{References}

Abd El-Ghany, S.E., Noum, W.M., Matar, Z., Zaky, Z.A., Aly, A.H.: Optimized bio-photonic sensor using 1D-photonic crystals as a blood hemoglobin sensor. Phys. Scripta 96, 035501 (2020). https://doi.org/ 10.1088/1402-4896/abd49c

Akimov, Y.: Optical resonances in Kretschmann and Otto configurations. Opt. Lett. 43, 1195-1198 (2018). https://doi.org/10.1364/OL.43.001195

Aly, A.H., Zaky, Z.A.: Ultra-sensitive photonic crystal cancer cells sensor with a high-quality factor. Cryogenics 104, 102991 (2019). https://doi.org/10.1016/j.cryogenics.2019.102991

Aly, A.H., Ryu, S.-W., Wu, C.-J.: Electromagnetic wave propagation characteristics in a one-dimensional metallic photonic crystal. J. Nonlinear Opt. Phys. Mater. 17, 255-264 (2008). https://doi.org/10.1142/ S0218863508004160

Aly, A.H., Zaky, Z.A., Shalaby, A.S., Ahmed, A.M., Vigneswaran, D.: Theoretical study of hybrid multifunctional one-dimensional photonic crystal as a flexible blood sugar sensor. Phys. Scr. 95, 035510 (2020). https://doi.org/10.1088/1402-4896/ab53f5

Aly, A.H., Mohamed, D., Zaky, Z.A., Matar, Z.S., Abd El-Gawaad, N.S., Shalaby, A.S., et al.: Novel biosensor detection of tuberculosis based on photonic band gap materials. Mater. Res.-Ibero-American J. Mater. 24, e20200483 (2021a). https://doi.org/10.1590/1980-5373-MR-2020-0483

Aly, A.H., Awasthi, S., Mohamed, A., Matar, Z., Mohaseb, M., Al-Dossari, M., et al.: Detection of reproductive hormones in females by using 1D photonic crystal-based simple reconfigurable biosensing design. Curr. Comput.-Aided Drug Des. 11, 1533 (2021b). https://doi.org/10.3390/cryst11121533

Balakrishnan, S., Najiminaini, M., Singh, M.R., Carson, J.J.: A study of angle dependent surface plasmon polaritons in nano-hole array structures. J. Appl. Phys. 120, 034302 (2016). https://doi.org/10.1063/1. 4958870

Bijalwan, A., Rastogi, V.: Gold-aluminum-based surface plasmon resonance sensor with a high quality factor and figure of merit for the detection of hemoglobin. Appl. Opt. 57, 9230-9237 (2018). https://doi. org/10.1364/AO.57.009230

Chabot, V., Miron, Y., Grandbois, M., Charette, P.G.: Long range surface plasmon resonance for increased sensitivity in living cell biosensing through greater probing depth. Sens. Actuators B Chem. 174, 94-101 (2012). https://doi.org/10.1016/j.snb.2012.08.028

Choi, S.H., Byun, K.M.: Investigation on an application of silver substrates for sensitive surface plasmon resonance imaging detection. JOSA A 27, 2229-2236 (2010). https://doi.org/10.1364/JOSAA.27. 002229

Choi, S.H., Kim, Y.L., Byun, K.M.: Graphene-on-silver substrates for sensitive surface plasmon resonance imaging biosensors. Opt. Express 19, 458-466 (2011). https://doi.org/10.1364/OE.19.000458

Dai, X., Jiang, L., Xiang, Y.: Low threshold optical bistability at terahertz frequencies with graphene surface plasmons. Sci. Rep. 5, 1-11 (2015). https://doi.org/10.1038/srep12271

El-Khozondar, H.J., Mahalakshmi, P., El-Khozondar, R.J., Ramanujam, N.R., Amiri, I., Yupapin, P.: Design of one dimensional refractive index sensor using ternary photonic crystal waveguide for plasma blood samples applications. Phys. E 111, 29-36 (2019). https://doi.org/10.1016/j.physe.2019.02.030

Esteban, Ó., Naranjo, F.B., Díaz-Herrera, N., Valdueza-Felip, S., Navarrete, M.-C., González-Cano, A.: High-sensitive SPR sensing with Indium Nitride as a dielectric overlay of optical fibers. Sens. Actuators B Chem. 158, 372-376 (2011). https://doi.org/10.1016/j.snb.2011.06.038

Foley, J.J., IV., Harutyunyan, H., Rosenmann, D., Divan, R., Wiederrecht, G.P., Gray, S.K.: When are surface plasmon polaritons excited in the Kretschmann-Raether configuration? Sci. Rep. 5, 1-5 (2015). https://doi.org/10.1038/srep09929

Gao, L., Lemarchand, F., Lequime, M.: Exploitation of multiple incidences spectrometric measurements for thin film reverse engineering. Opt. Express 20, 15734-15751 (2012). https://doi.org/10.1364/OE.20. 015734

Guerinik, A., Tayeboun, F.: Enhancement in sensitivity of a surface plasmon resonance sensor with Al X GA 1-X as, 70\% Al. Prog. Electromagn. Res. 92, 125-132 (2020). https://doi.org/10.2528/PIERL 20022601 
Homola, J.: Surface plasmon resonance sensors for detection of chemical and biological species. Chem. Rev. 108, 462-493 (2008). https://doi.org/10.1021/cr068107d

Johnson, P., Christy, R.: Optical constants of transition metals: Ti, v, cr, mn, fe, co, ni, and pd. Phys. Rev. B 9, 5056 (1974). https://doi.org/10.1103/PhysRevB.9.5056

Kim, D.: Nanostructure-based localized surface plasmon resonance biosensors. In: Optical Guided-wave Chemical and Biosensors I, pp. 181-207. https://doi.org/10.1007/978-3-540-88242-8_7 (2010)

Kushwaha, A.S., Kumar, A., Kumar, R., Srivastava, S.: A study of surface plasmon resonance (SPR) based biosensor with improved sensitivity. In: Photonics and Nanostructures-Fundamentals and Applications, vol. 31, pp. 99-106. https://doi.org/10.1016/j.photonics.2018.06.003 (2018)

Lahav, A., Auslender, M., Abdulhalim, I.: Sensitivity enhancement of guided-wave surface-plasmon resonance sensors. Opt. Lett. 33, 2539-2541 (2008). https://doi.org/10.1364/OL.33.002539

Liu, Y., Sajjadi, B., Chen, W.-Y., Chatterjee, R.: Ultrasound-assisted amine functionalized graphene oxide for enhanced CO2 adsorption. Fuel 247, 10-18 (2019). https://doi.org/10.1016/j.fuel.2019.03.011

Maurya, J., Prajapati, Y.: A comparative study of different metal and prism in the surface plasmon resonance biosensor having MoS 2-graphene. Opt. Quant. Electron. 48, 280 (2016). https://doi.org/10. 1007/s11082-016-0562-6

Meradi, K., Tayeboun, F., Benkabou, F.: Surface plasmon sensor based on a dual dielectric-silver photonic crystal. J. Russ. Laser Res. 37, 180-184 (2016). https://doi.org/10.1007/s10946-016-9558-8

Meshginqalam, B., Barvestani, J.: Performance enhancement of SPR biosensor based on phosphorene and transition metal dichalcogenides for sensing DNA hybridization. IEEE Sens. J. 18, 7537-7543 (2018). https://doi.org/10.1109/JSEN.2018.2861829

Ooi, K.J., Bai, P., Gu, M.X., Ang, L.K.: Plasmonic coupled-cavity system for enhancement of surface plasmon localization in plasmonic detectors. Nanotechnology 23, 275201 (2012). https://doi.org/10.1088/ 0957-4484/23/27/275201

Ouyang, Q., Zeng, S., Dinh, X.-Q., Coquet, P., Yong, K.-T.: Sensitivity enhancement of MoS2 nanosheet based surface plasmon resonance biosensor. Proc. Eng. 140, 134-139 (2016). https://doi.org/10.1016/j. proeng.2015.08.1114

Prather, D.W., Shi, S., Sharkawy, A., Murakowski, J., Schneider, G.: Photonic crystals. Theory Appl. Fabrication (2009). https://doi.org/10.1364/OPN.13.6.000016

Rahman, M.S., Anower, M., Hasan, M., Rikta, K.A.: Sensitivity enhancement of MoS2-graphene hybrid structure based surface plasmon resonance biosensor using air gap. Sens. Lett. 15, 510-516 (2017a). https://doi.org/10.1166/s1.2017.3842

Rahman, M.S., Anower, M.S., Hasan, M.R., Hossain, M.B., Haque, M.I.: Design and numerical analysis of highly sensitive Au-MoS2-graphene based hybrid surface plasmon resonance biosensor. Opt. Commun. 396, 36-43 (2017b). https://doi.org/10.1016/j.optcom.2017.03.035

Rahman MS, Rikta K, Abdulrazak LF, Anower M (2020) Enhanced performance of SnSe-Graphene hybrid photonic surface plasmon refractive sensor for biosensing applications. Photonics Nanostructures-Fundamentals and Applications. 39: 100. Doi: https://doi.org/10.1016/j.photonics.2020.100779

Ramanujam, N.R., Amiri, I., Taya, S.A., Olyaee, S., Udaiyakumar, R., Pandian, A.P., et al.: Enhanced sensitivity of cancer cell using one dimensional nano composite material coated photonic crystal. Microsyst. Technol. 25, 189-196 (2019). https://doi.org/10.1007/s00542-018-3947-6

Sabra, W., Azzam, S.I., Song, M., Povolotskyi, M., Aly, A.H., Kildishev, A.V.: Plasmonic metasurfaces for subtractive color filtering: optimized nonlinear regression models. Opt. Lett. 43, 4815-4818 (2018). https://doi.org/10.1364/OL.43.004815

Sahu, K., Mohanty, S.K., Gupta, P.K.: He-Ne laser $(632.8 \mathrm{~nm})$ pre-irradiation gives protection against DNA damage induced by a near-infrared trapping beam. J. Biophotonics 2, 140-144 (2009). https://doi.org/ 10.1002/jbio.200810041

Shalabney, A., Abdulhalim, I.: Sensitivity-enhancement methods for surface plasmon sensors. Laser Photonics Rev. 5, 571-606 (2011). https://doi.org/10.1002/lpor.201000009

Siefke, T., Kroker, S., Pfeiffer, K., Puffky, O., Dietrich, K., Franta, D., et al.: Materials pushing the application limits of wire grid polarizers further into the deep ultraviolet spectral range. Adv. Opt. Mater. 4, 1780-1786 (2016). https://doi.org/10.1002/adom.201600250

Singh, M.R., Black, K.: Anomalous dipole-dipole interaction in an ensemble of quantum emitters and metallic nanoparticle hybrids. J. Phys. Chem. C 122, 26584-26591 (2018). https://doi.org/10.1021/acs. jpcc.8b06352

Singh, V.V., Gupta, G., Batra, A., Nigam, A.K., Boopathi, M., Gutch, P.K., et al.: Greener electrochemical synthesis of high quality graphene nanosheets directly from pencil and its SPR sensing application. Adv. Funct. Mater. 22, 2352-2362 (2012). https://doi.org/10.1002/adfm.201102525 
Singh, M.R., Brzozowski, M., Racknor, C.: Induced transparencies in metamaterial waveguides doped with quantum dots. J. Phys. D Appl. Phys. 48, 145301 (2015). https://doi.org/10.1088/0022-3727/48/14/ 145301

Sreekanth, K.V., Zeng, S., Yong, K.-T., Yu, T.: Sensitivity enhanced biosensor using graphene-based onedimensional photonic crystal. Sens. Actuators B Chem. 182, 424-428 (2013). https://doi.org/10. 1016/j.snb.2013.03.039

Tammam, M.T., Zaky, Z.A., Sharma, A., Matar, Z.S., Aly, A., Mohaseb, M.A.: Defected photonic crystal array using porous $\mathrm{GaN}$ as malaria sensor, presented at the IOP Conference Series: Materials Science and Engineering. https://doi.org/10.1088/1757-899X/1171/1/012005 (2021)

Verma, R., Gupta, B.D., Jha, R.: Sensitivity enhancement of a surface plasmon resonance based biomolecules sensor using graphene and silicon layers. Sens. Actuators B Chem. 160, 623-631 (2011). https:// doi.org/10.1016/j.snb.2011.08.039

Verma, A., Prakash, A., Tripathi, R.: Sensitivity enhancement of surface plasmon resonance biosensor using graphene and air gap. Opt. Commun. 357, 106-112 (2015). https://doi.org/10.1016/j.optcom.2015.08. 076

Wu, L., Chu, H., Koh, W., Li, E.: Highly sensitive graphene biosensors based on surface plasmon resonance. Opt. Express 18, 14395-14400 (2010). https://doi.org/10.1364/OE.18.014395

Wu, L., Jia, Y., Jiang, L., Guo, J., Dai, X., Xiang, Y., et al.: Sensitivity improved SPR biosensor based on the $\mathrm{MoS}_{2}$ /graphene-aluminum hybrid structure. J. Lightwave Technol. 35, 82-87 (2016). https://doi.org/ 10.1109/JLT.2016.2624982

Wu, L., Guo, J., Wang, Q., Lu, S., Dai, X., Xiang, Y., et al.: Sensitivity enhancement by using few-layer black phosphorus-graphene/TMDCs heterostructure in surface plasmon resonance biochemical sensor. Sens. Actuators B Chem. 249, 542-548 (2017). https://doi.org/10.1016/j.snb.2017.04.110

Xiang, Y., Dai, X., Guo, J., Wen, S., Tang, D.: Tunable optical bistability at the graphene-covered nonlinear interface. Appl. Phys. Lett. 104, 051108 (2014). https://doi.org/10.1063/1.4863927

Xinglong, Y., Dingxin, W., Zibo, Y.: Simulation and analysis of surface plasmon resonance biosensor based on phase detection. Sens. Actuators B Chem. 91, 285-290 (2003). https://doi.org/10.1016/S09254005(03)00105-9

Zaky, Z.A., Aly, A.H.: Theoretical study of a tunable low-temperature photonic crystal sensor using dielectric-superconductor nanocomposite layers. J. Supercond. Novel Magn. 33, 2983-2990 (2020). https:// doi.org/10.1007/s10948-020-05584-1

Zaky, Z.A., Aly, A.H.: Modeling of a biosensor using Tamm resonance excited by graphene. Appl. Opt. 60, 1411-1419 (2021a). https://doi.org/10.1364/AO.412896

Zaky, Z.A., Aly, A.H.: Gyroidal graphene/porous silicon array for exciting optical Tamm state as optical sensor. Sci. Rep. 11, 19389 (2021b). https://doi.org/10.1038/s41598-021-98305-0

Zaky, Z.A., Aly, A.H.: Highly sensitive salinity and temperature sensor using Tamm resonance. Plasmonics 16, 2315-2325 (2021c). https://doi.org/10.1007/s11468-021-01487-6

Zaky, Z.A., Ahmed, A.M., Shalaby, A.S., Aly, A.H.: Refractive index gas sensor based on the Tamm state in a one-dimensional photonic crystal: theoretical optimisation. Sci. Rep. 10, 9736 (2020). https://doi.org/ 10.1038/s41598-020-66427-6

Zaky, Z.A., Sharma, A., Aly, A.H.: Gyroidal graphene for exciting Tamm plasmon polariton as refractive index sensor: theoretical study. Opt. Mater. 122, 111684 (2021a). https://doi.org/10.1016/j.optmat. 2021.111684

Zaky, Z.A., Ahmed, A.M., Aly, A.H.: Remote temperature sensor based on Tamm resonance. SILICON (2021b). https://doi.org/10.1007/s12633-021-01064-w

Zaky, Z.A., Sharma, A., Alamri, S., Aly, A.H.: Theoretical evaluation of the refractive index sensing capability using the coupling of Tamm-Fano resonance in one-dimensional photonic crystals. Appl. Nanosci. 11, 2261-2270 (2021c). https://doi.org/10.1007/s13204-021-01965-7

Zaky, Z.A., Sharma, A., Alamri, S., Saleh, N., Aly, A.H.: Detection of fat concentration in milk using ternary photonic crystal. SILICON (2021d). https://doi.org/10.1007/s12633-021-01379-8

Zaky, Z.A., Sharma, A., Aly, A.H.: Tamm plasmon polariton as refractive index sensor excited by Gyroid metals/porous $\mathrm{Ta}_{2} \mathrm{O}_{5}$ photonic crystal. Plasmonics (2021e). https://doi.org/10.1007/ s11468-021-01559-7

Zeng, S., Hu, S., Xia, J., Anderson, T., Dinh, X.-Q., Meng, X.-M., et al.: Graphene-MoS 2 hybrid nanostructures enhanced surface plasmon resonance biosensors. Sens. Actuators B Chem. 207, 801-810 (2015). https://doi.org/10.1016/j.snb.2014.10.124

Publisher's Note Springer Nature remains neutral with regard to jurisdictional claims in published maps and institutional affiliations. 